\title{
ANÁLISIS DE LA RESOLUCIÓN 60/251 MEDIANTE LA CUAL SE CREÓ EL CONSEJO DE DERECHOS HUMANOS DE LA ONU
}

\section{Analysis of Resolution $60 / 251$ by means of which the United Nations Human Rights Council was created}

\author{
Janneth Milena Pacheco Baquero* \\ Ivo García Vargas**
}

Fecha de entrega: 20 de marzo de 2007

Fecha de aprobación: 11 mayo de 2007

Fecha de evaluación: 21de junio de 2007

\section{Resumen}

Las graves violaciones al derecho internacional humanitario ocurridas durante la segunda guerra mundial, motivaron a una parte importante de la sociedad internacional a crear la Comisión de Derechos Humanos como órgano subsidiario del Ecosoc, en el seno de las Naciones Unidas. A pesar de los

* Docente facultad de Derecho Universidad Santo Tomas cátedra de Derecho Internacional Público y Derecho Comunitario.

** Docente Facultad de Derecho Universidad Santo Tomas de DDHH y DIH. 
importantes logros que alcanzó esta Comisión en el ejercicio de la función promotora y de protección de los derechos humanos, su fuerte politización, los nuevos retos en la materia y la necesidad de fortalecer institucionalmente el tema, hicieron que ésta Comisión fuera reemplazada a través de la Resolución 60/251 de 2006 de la Asamblea General de la ONU por un Consejo de Derechos Humanos, órgano más representativo, permanente, imparcial , y con mayores responsabilidades en el proceso de atención, evaluación y cumplimiento de las obligaciones en derechos humanos por parte de los Estados miembros.

Para el caso colombiano, la extinta Comisión de Derechos Humanos hacía un seguimiento permanente del conflicto armado, tarea que será ahora asumida por el nuevo Consejo de Derechos Humanos a quien le corresponderá particularmente hacer el seguimiento a las recomendaciones hechas por la antigua Comisión.

Un elemento innovador que introduce la resolución en comento, es la aplicación del mecanismo de examen periódico universal con el que se pretende evaluar a todos los países miembros sin excepción en el cumplimiento de sus compromisos con los derechos humanos. Sin embargo, y aunque este órgano sin duda se visualiza como una institución más sólida y eficaz, sigue requiriendo para alcanzar sus objetivos y más allá de meros intereses políticos, del compromiso y la buena voluntad de los Estados miembros del Consejo, los gobiernos y demás participantes.

\section{Palabras clave}

Resolución 60/251, derechos humanos, Comisión de Derechos Humanos, Consejo de Derechos Humanos, conflicto armado colombiano.

\section{Abstract}

The serious violations to the international humanitarian law that happened during World War II motivated an important part of the international society to create the Human Rights Committee as an ancillary organ of the Ecosoc inside the United Nations. Although this committee obtained important achievements in the exercise of the functions of promoting and protecting the human rights, its strong management by politics, the new challenges in the subject and the need to fortify in an institutional way the matter, made this committee to be replaced through the resolution 60/251 of 2006 of the ONU's General Assembly by a Human Rights Council , a more representative, permanent, impartial organ, with more responsibilities in the process of attention, evaluation and fulfillment of the obligations in the theme of Human Rights by the states members .

In the Colombian case, the extinct Human Rights committee did a permanent following of the armed conflict, work that now will be assumed by the new Human Rights council, that now will follow the recommendations done by the old committee.

An innovative element in the mentioned resolution is a mechanism of universal periodic exam which all the countries that are members will be evaluated without exception in the accomplishment of their compromises with the Human Rights. This organ will require the compromise and the good will of the States that are members of the Council, the governments and all the other participants. 


\section{Key words}

Resolution 60/251, Human Rights, human rights committee, human rights council, Colombian armed conflict.

\section{ANTECEDENTES GENERALES}

\subsection{La comisión de derechos humanos de la ONU}

La Comisión de Derechos Humanos de la Organización de las Naciones Unidas (que en adelante denominaremos la CDH era uno de los órganos subsidiarios del Consejo Económico y Social, Ecosoc). La CDH fue creada en 1946 con la finalidad de ocuparse de los asuntos en materia de derechos humanos (Roulet, 1997, pp.25 y ss).

Recordemos que los Estados fundadores de las Naciones Unidas ${ }^{2}$ estaban particularmente preocupados por la dramática realidad de la guerra: la violación de los derechos humanos y del derecho internacional humanitario. Como consecuencia de lo anterior, los objetivos fundamentales de la organización ${ }^{2}$ se concretaron en:

- Mantener la paz y la seguridad internacionales.

- Establecer relaciones de amistad, respeto, tolerancia y cooperación entre las naciones.

- Fomentar el respeto a los derechos humanos y a las libertades fundamentales.

- Asegurar el progreso económico y social de todos los pueblos.
- Coordinar los esfuerzos nacionales para alcanzar todos esos objetivos.

La CDH nace como un órgano subsidiario del Ecosoc, integrada por representantes de 53 Estados parte, elegidos con sus respectivos suplentes por un periodo de tres años; se reunían seis semanas al año en la sede de la ONU en Ginebra (Suiza). Durante el período ordinario de sesiones anuales, la Comisión solía aprobar alrededor de un centenar de resoluciones, decisiones y declaraciones de la presidencia sobre temas de interés común entre las regiones. La CDH recibía el apoyo de la Subcomisión de Promoción y Protección de los Derechos Humanos, de varios grupos de trabajo, de la red de expertos, y de los representantes y relatores que presentaban informes sobre temas específicos.

Las funciones de la extinta Comisión eran:

- La promoción de los derechos humanos.

- La protección de los derechos humanos.

La primera consistía en identificar problemas, señalar las insuficiencias en la legislación nacional o determinar qué violaciones ocurrían, para buscar y proponer soluciones que impidieran que se produjeran en el futuro situaciones similares. Esta era una labor esencialmente preventiva, realizada mediante la preparación de estudios, investigaciones e informes y la elaboración de proyectos de normas internacionales.

1 Dentro de los que se encuentra Colombia.

2 Carta de las Naciones Unidas. 
La segunda, consistía en la protección de los derechos humanos, asegurando, de esta manera, que los Estados respetaran estrictamente los derechos humanos establecidos en los tratados internacionales y que se evidenciaran y castigaran las violaciones comprobadas.

La Comisión no era una corte ni podía sancionar a los Estados, pero en sus últimos años estableció distintos procedimientos para supervisar la situación de los derechos humanos en los distintos países y para investigar denuncias de violaciones de esos derechos (tortura, desaparición forzada) mediante grupos de trabajo o designando un experto o relator. Por otra parte, la Comisión tenía un procedimiento de presentación de denuncias individuales sobre violaciones sistemáticas y masivas de los derechos humanos conocida como procedimiento confidencial 1503, el cual fue establecido en 1970 por la resolución 1503 del Ecosoc.

Indudablemente dentro de sus límites, la CDH jugó un rol muy importante desde su creación hasta el momento de su extinción. La CDH fue ampliamente criticada por haberse dedicado, durante un largo periodo, exclusivamente a acusar a los países "periféricos" (en muchos casos bajo la presión de los Estados Unidos), aunque a pesar de esto, en los últimos años, se notaron dos cambios importantes en la Comisión:

- Varios de sus relatores comenzaron a ocuparse de las violaciones a los derechos humanos cometidas por los Estados Unidos, tendencia que culminó con el informe de cinco relatores miembros de la Comisión sobre las torturas y malos tratos en el campo de concentración de Guantánamo³ .
- El otro cambio importante fue el creciente interés demostrado en la Comisión por los derechos económicos, sociales y culturales (DESC), temas que siempre encontraron una fuerte oposición por parte de los Estados Unidos, que ha terminado aislado en la Comisión en razón a esa postura. Las críticas a las que fue sometida la $\mathrm{CDH}$ durante su existencia (politización, ineficiencia, ineficacia, etc.), dieron pie a la reciente creación del Consejo de Derechos Humanos ${ }^{4}$.

\subsection{La creación del Consejo de Derechos Humanos}

La Comisión de Derechos Humanos, tal como existía, tenía considerables logros de los que podía enorgullecerse, pero su capacidad de desempeñar sus funciones se vio superada por nuevas necesidades y debilitada por la politización durante sus períodos de sesiones y el carácter selectivo de su labor.

El Consejo de Derechos Humanos tiene, en estos momentos, grandes desafíos que deberán ser asumidos responsablemente, para superar la crisis en materia de derechos humanos a nivel mundial. En su informe titulado "Un concepto más amplio de la libertad: desarrollo, seguridad y derechos humanos para todos" ${ }^{5}$, el Secretario General de la ONU hizo las siguientes observaciones y propuestas:

Para que las Naciones Unidas cumplan las expectativas de los hombres y las mujeres de todo el mundo y, de hecho, para que la Organización asigne a la causa de los derechos humanos la

3 E/CN.4/2006/120, Documento de la oficina del Alto Comisionado de las Naciones Unidas para los Derechos Humanos.

4 El Secretario General de la ONU en un mensaje dirigido al presidente de la Asamblea General el 14 de abril de 2005 puso de presente su preocupación por las deficiencias de la CDH; algunos problemas crecientes, tanto de percepción como sustantivos, asociados con la Comisión, lo que permitiría realizar una nueva y profunda evaluación de la eficacia del mecanismo intergubernamental con que cuentan las Naciones Unidas para enfrentar los problemas en la esfera de los derechos humanos.

5 Informe (A/59/2005) de marzo de 2005 el Secretario General de la ONU (propuso la creación de un Consejo de Derechos Humanos) a la Asamblea General http://ap.ohchr.org/documents/dpage_s.aspx?m=117. 
misma importancia que a las causas de la seguridad y el desarrollo, los Estados Miembros deberían convenir en reemplazar la Comisión de Derechos Humanos por un Consejo de Derechos Humanos de carácter permanente y con una composición más reducida.

Los Estados Miembros deberán decidir si desean que el Consejo de Derechos Humanos sea un órgano principal de las Naciones Unidas o un órgano subsidiario de la Asamblea General, pero en ambos casos sus miembros serían elegidos directamente por la Asamblea General por el voto de una mayoría de dos tercios de los miembros presentes y votantes. La creación del Consejo situaría a los derechos humanos en una posición de mayor autoridad, acorde con la primacía que se atribuye a los derechos humanos en la Carta de las Naciones Unidas. Los Estados Miembros deberán determinar la composición del Consejo y la duración del mandato de sus miembros. Los miembros del Consejo deberían comprometerse a acatar las normas de derechos humanos más rigurosas.

Según la propuesta del Secretario General, el Consejo de Derechos Humanos sería un órgano permanente, autorizado para reunirse periódicamente, ocuparse de crisis inminentes, y examinar cuestiones de derechos humanos en forma oportuna y minuciosa. Llevar los debates sobre los derechos humanos más allá de un período de sesiones de seis semanas de duración, que tienen una gran carga política, también permitiría dedicar más tiempo, al seguimiento sustantivo de la aplicación de decisiones y resoluciones. Los miembros serían elegidos por todos los integrantes de la Asamblea General, lo que daría lugar a una mejor rendición de cuentas y permitiría que el órgano fuera más representativo.
El Consejo de Derechos Humanos, de acuerdo a las recomendaciones de la Secretaría General de la $\mathrm{ONU}^{6}$, debería tener una función definida especialmente para actuar como mecanismo de examen entre los países; su misión principal sería evaluar el cumplimiento de las obligaciones relacionadas con los derechos humanos por parte de los Estados Miembros, de esta manera se concretaría el principio de universalidad e indivisibilidad de los derechos humanos.

También debería prestar la misma atención a los derechos civiles, políticos, económicos, sociales y culturales (DESC), así como al derecho al desarrollo. Por haber sido elegidos directamente por la Asamblea General, (que es el principal órgano legislativo de las Naciones Unidas), Ios países miembros tendrían más autoridad que la Comisión, que era un órgano subsidiario del Consejo Económico y Social (Ecosoc).

La creación del Consejo de Derechos Humanos es la respuesta a la necesidad de fortalecer institucionalmente al interior de la ONU el tema de los derechos humanos, lo cual necesariamente tendrá repercusiones en los Estados miembros. Al elevar la Comisión de Derechos Humanos a la categoría de Consejo propiamente dicho, se acordó a los derechos humanos el alto grado de prioridad que revisten en la Carta de las Naciones Unidas.

A continuación se ofrece un listado de los organismos y programas de las Naciones Unidas que se ocupan especialmente de los derechos humanos ${ }^{7}$ :

$6 \quad$ El Secretario General describió en más detalle la propuesta de una nueva función fundamental de examen entre los países en el Consejo de Derechos Humanos, en un discurso pronunciado ante la Comisión de Derechos Humanos el 7 de abril de 2005. http://ap.ohchr.org/documents/ dpage_s.aspx?m=117

7 Tomado de la página Web del Colegio Universitario Henry Dunant (Ginebra, Suiza), http://ap.ohchr.org/documents/dpage_s.aspx?m=117. 


\section{Estructura organizativa de}

las Naciones Unidas en materia

\section{de derechos humanos}

\section{CONSEJO DE SEGURIDAD (CS)}

- Tribunal Penal Internacional para la ex-Yugoslavia / La Haye

- Tribunal Penal Internacional para Rwanda / Arusha

\section{CONSEJO DE ADMINISTRACIÓN FIDUCIARIA} New York

\section{CORTE INTERNACIONAL DE JUSTICIA}

La Haye

\section{SECRETARÍA}

- Secretario-General. Presenta sus informes a la AG, CS, ECOSOC y CDH).

- Alto Comisionado para los Derechos Humanos. Presenta sus informes a la AG, ECOSOC y CDH). Cooperación Técnica. Presencia en el terreno.

\section{ASAMBLEA GENERAL (AG)}

New York

- Consejo de Derechos Humanos (Ginebra)
- Comité Especial: encargado de investigar las prácticas israelíes que afecten a los derechos humanos del pueblo palestino $y$ otros habitantes árabes de los territorios ocupados (en inglés). Presenta sus informes a la AG.

\section{CONSEJO ECONÓMICO Y SOCIAL}

(Ecosoc)

New York. Presenta sus informes a la AG.

Órganos subsidiarios (presentan sus informes al Ecosoc), incluidas :

- Comisión de Prevención del Delito y Justicia Penal

- Comisión de la Condición Jurídica y Social de la Mujer / New York

Órgano subsidiario de la CDH :

- Subcomisión de Prevención de Discriminaciones y Protección a las Minorías

Presenta sus informes a la CDH. Estudios de los Relatores Especiales. Grupos de trabajo. 


\section{SISTEMA DE LAS NACIONES UNIDAS}

Mecanismos establecidos en virtud de tratados (órganos de vigilancia de los tratados) : Comité de Derechos Económicos, Sociales y Culturales. Ginebra. Presenta sus informes al ECOSOC.

- Comité de Derechos Humanos. Ginebra, New York. Presenta sus informes a la AG.

- Comité contra la Tortura. Ginebra. Presenta sus informes a la AG.

- Comité para la Eliminación de la Discriminación Racial. Ginebra. Presenta sus informes a la AG.

- Comité para la Eliminación de la Discriminación contra la Mujer. New York. Presenta sus informes a la AG.

- Comité de los Derechos del Niño. Ginebra. Presenta sus informes a la AG.

\section{EL CONSEJO DE DERECHOS HUMANOS $Y$ LOS ESTADOS MIEMBROS}

La creación del Consejo de Derechos Humanos constituye una importante mejoría en el trabajo de promoción y defensa de los derechos humanos a nivel mundial debido a que se establecen una serie de obligaciones para los países miembros dentro de las cuales destacamos:

a. Una Evaluación Periódica Universal que garantiza que el historial de cada uno de los 191 Estados Miembros de las Naciones Unidas, comenzando por los miembros del Consejo mismo, sean evaluados constantemente con el propósito de mejorar las condiciones de los derechos humanos en todo el mundo. Todos los Estados deberán rendir cuentas por sus deficiencias o metas no cumplidas.

b. El Consejo podrá coordinar un número mayor de reuniones durante el año y por periodos más prolongados que la Comisión. Tam- bién contará con un sistema más simple y efectivo para convocar a sesiones especiales con el objetivo de responder rápidamente a las crisis relacionadas con asuntos de derechos humanos.

c. Cualquier miembro del Consejo, que cometa violaciones contra los derechos humanos, de manera sistemática podrá ser suspendido siempre que dos tercios de la Asamblea General vote a favor de esta medida; sin lugar a dudas, es esencial que el Consejo adopte medidas y métodos de trabajo que le permitan emprender con prontitud acciones efectivas para promover los derechos humanos y proteger a los titulares de estos derechos en todo el mundo.

d. El Consejo debe también demostrar su capacidad de actuar ante situaciones urgentes (derechos humanos), superando de esta manera los primeros obstáculos que se le han presentado frente a las decisiones y las medidas urgentes no resueltas. 
El Consejo de Derechos Humanos de la ONU, dentro del marco de su competencia, ha evaluado varias cuestiones claves (la compleja crisis de derechos humanos de Darfur, las consecuencias de la violencia en el Líbano y los territorios ocupados desde el punto de vista humanitario y el deterioro de la situación de los derechos humanos en Sri Lanka y en Colombia), ha examinado y sometido a debate, con un detenimiento sin precedentes, los informes de los procedimientos especiales y recibido informes de actualización de los grupos de trabajo encargados de completar su arquitectura. Así mismo, ha examinado en profundidad algunos de los principales retos que se le plantean a la comunidad internacional en materia de derechos humanos.

No obstante lo anterior, organizaciones como Amnistía Internacional ${ }^{8}$, consideran motivo de gran preocupación que hasta la fecha no se haya tomado ninguna decisión para proteger con medidas concretas los derechos humanos. Según la ONG mencionada, es esencial, para el éxito, a largo plazo, del Consejo de Derechos Humanos, que se tomen medidas efectivas. Amnistía Internacional propone, para lograr el objetivo de mejorar el cumplimiento de las obligaciones y compromisos de cada Estado en materia de derechos humanos, y, para satisfacer fielmente los requisitos establecidos en la resolución 60/251, que se respeten los siguientes principios en el mecanismo de examen periódico universal ${ }^{9}$ :

1. Igualdad de trato y no selectividad: la realización y las modalidades del examen deben ser las mismas para todos los Estados miembros de las Naciones Unidas. Esto debe aplicarse también a la periodicidad del examen, los procedimientos seguidos y las normas co- munes básicas en las que se basa el examen. No obstante, las cuestiones sustanciales abordadas en el examen y sus resultados deben ser específicos de cada país.

2. Universalidad: el examen debe estar diseñado para evaluar la promoción y la protección de todos los derechos humanos en todos los Estados. El proceso de preparación debe considerar el cumplimiento de todas las obligaciones y compromisos en materia de derechos humanos en el Estado, objeto del examen, pero, para garantizar la eficacia, cada examen debe centrarse en cuestiones específicas de cada Estado, ya que esa es la mejor manera de mejorar el disfrute de Ios derechos en el Estado objeto del examen.

3. Transparencia: el examen debe ser público y transparente en todos los aspectos para todos los países afectados. La transparencia plena debe aplicarse a la información que se utiliza como base para el examen.

4. Eficiencia: el examen debe hacer el mejor uso posible de los recursos de que dispone el Consejo de Derechos Humanos. Un proceso eficiente exige una preparación exhaustiva de cada examen, un compromiso de cooperar por parte de todas las partes implicadas, decisiones y recomendaciones específicas en el resultado del examen, y una aplicación sostenida de esas decisiones y recomendaciones.

5. Efectividad: el examen debe tratar de establecer medidas, cuya aplicación se pueda esperar en un grado razonable, y que lleven a los Estados a cumplir mejor sus obligaciones y compromisos en materia de derechos

8 Amnistía Internacional, observaciones al Consejo de Derechos Humanos e informe de la situación mundial de los Derechos Humanos 2006 http://ap.ohchr.org/documents/dpage_s.aspx?m=117.

9 Ibíd. 
humanos y a brindar una mayor protección a los titulares de los derechos. El proceso de examen debe basarse en información adecuada y abundante y debe tener en cuenta la capacidad y los recursos del Estado examinado, de otros gobiernos y de las partes del sistema de la ONU que puedan contribuir a la aplicación de las medidas recomendadas en el examen.

\section{Complementariedad con otros elementos} del programa de derechos humanos de las Naciones Unidas: el examen debe basarse en los demás elementos del programa de derechos humanos de la ONU, y reforzarlos, especialmente, los órganos de vigilancia de los tratados y los procedimientos especiales. Además de evitar la duplicación con los órganos de derechos humanos, debe respetar el mandato y las prioridades de otros mecanismos, órganos y oficinas de derechos humanos de la ONU. El mecanismo de examen periódico universal es uno de los medios mediante los cuales el Consejo puede abordar situaciones en países específicos.

7. Credibilidad: la información que se utilice como base para el examen, el proceso de examen en sí (incluido el diálogo interactivo) y sus resultados deben ser creíbles para quienes participen en el examen y para el público informado. Aunque el examen periódico universal debe guiarse por un diálogo y una cooperación internacional constructivos, también debe ser franco y directo en lo que se refiere a abordar las deficiencias de los Estados a la hora de cumplir sus obligaciones y compromisos en materia de derechos humanos.

8. Continuidad: el examen debe ser un proceso con coherencia interna que englobe la preparación, el examen basado en un diálogo interactivo, el resultado y el seguimien- to. Cada examen debe formar parte de un ciclo que conduzca a una mejora constante del cumplimiento de las obligaciones y compromisos del Estado, en materia de derechos humanos y en el que los exámenes subsiguientes se basen en el resultado del examen precedente.

9. Cooperación: como mecanismo de cooperación, basado en un diálogo interactivo, el examen debe estar diseñado para promover la cooperación entre todos los participantes, incluido el Estado objeto del examen.

10. Plena participación del país afectado: esto supone que todos los sectores pertinentes de la sociedad del país, objeto del examen, incluidos su gobierno, su sociedad civil y sus instituciones nacionales independientes de derechos humanos, tienen la oportunidad de contribuir de forma efectiva a la preparación del examen, el diálogo interactivo, el resultado y su seguimiento.

\section{ESTRUCTURA DE LA RESOLUCIÓN AG 60/251 DE 2006}

La resolución 60/251, aprobada el 15 de marzo de 2006, por la Asamblea General de Naciones Unidas creó el Consejo de Derechos Humanos como órgano subsidiario a ésta, en la que se distinguen los siguientes aspectos:

En primer lugar, se encuentra que la base ideológica de esta resolución son los principios y propósitos señalados en la Carta de Naciones Unidas así como la Declaración de los Derechos Humanos, y el Pacto Internacional de Derechos Civiles y Políticos entre otros instrumentos de derechos humanos, por lo que es dentro de ese mismo marco que, la resolución que, diríamos, equivale a la Carta Constitutiva del Consejo de Derechos Humanos le asigna como principal función: 
La promoción del respeto universal de la protección de todos los derechos humanos y libertades fundamentales de todas las personas, sin distinciones de ningún tipo y de forma justa y equitativa ${ }^{10}$.

El segundo aspecto que se encuentra en la resolución, es el procedimiento que se establece para adquirir la calidad de miembro del Consejo de Derechos Humanos. Así es, la resolución implementa un nuevo procedimiento con el cual, al menos en teoría, se pretende hacer más transparente y menos politizado la composición del nuevo Consejo, que es ahora más reducido y tiene una duración permanente, en el cual sus miembros son elegidos por mayoría de dos tercios de la Asamblea General y quienes no pueden optar por la reelección inmediata después de dos períodos consecutivos ${ }^{11}$, tratando de esta manera superar una de las más severas críticas que recibió durante su existencia la Comisión de Derechos Humanos.

En este mismo sentido, encontramos que se exige a los Estados miembros, tener en cuenta como criterio de evaluación al momento de conocer las candidaturas, "la contribución de los candidatos a la promoción y protección de los derechos humanos y las promesas y compromisos voluntarios que hayan hecho al respecto"12, por lo que se entiende, este órgano estará compuesto por los países más comprometidos a nivel internacional con el tema de la promoción, protección y respeto de los derechos humanos.

En tercer lugar y a manera de control, se incluyó una figura nueva como es el mecanismo del examen periódico universal aplicable a todos los Estados, incluidos los elegidos en el Consejo; ins- trumento con el cual se pretende medir los Estados de manera periódica en el cumplimiento de sus obligaciones y compromisos en materia de derechos humanos ${ }^{13}$.

Por último, revisando las competencias y funciones que tiene el nuevo Consejo de Derecho Humanos se destacan su responsabilidad en "la promoción y el respeto universal por la protección de todos los derechos humanos y libertades fundamentales sin ninguna distinción y de una manera justa y equitativa". En términos más precisos, señala la resolución que el Consejo DH se ocupará de:

- Conocer las situaciones en que se infrinjan los derechos humanos, incluidas las infracciones graves y sistemáticas.

- Coordinar e incorporar los derechos humanos en la actividad general del sistema de las Naciones Unidas.

- impulsar la promoción y protección de todos los derechos humanos, incluido el derecho al desarrollo.

- Promover la educación en derechos humanos.

- Prestar servicios de asesoramiento a solicitud de los Estados interesados.

- Servir de foro para el diálogo sobre cuestiones temáticas relativas a todos los derechos humanos.

- Contribuir al desarrollo del derecho internacional de los derechos humanos.

\footnotetext{
10 Resolución 60/251 de la Asamblea General, aprobada el 15 de marzo de 2006 por 170 votos a favor, 4 en contra (Estados Unidos, Israel, Islas Marshall y Palau) y 3 abstenciones (Belarús, Irán y Venezuela. http://ap.ohchr.org/documents/dpage_s.aspx?m=117.

11 Párrafo 7 de la Resolución 60/251.

12 Párrafo 8 de la Resolución 60/251.

13 Párrafo 5 numeral e) de la Resolución 60/251
} 
- Promover el cumplimiento de las obligaciones de los Estados en materia de derechos humanos.

- Facilitar, prevenir, respondery supervisar la labor de la Oficina del Alto Comisionado para los Derechos Humanos de las Naciones Unidas, funciones que resultan familiares en su mayoría con las que ya ejecutaba la anterior Comisión de Derechos Humanos ${ }^{13}$.

También, entre sus funciones, se observa que se le reconoce al Consejo de Derechos Humanos cierto poder normativo, en la medida que puede "formular recomendaciones a la Asamblea General para seguir desarrollando el derecho internacional en la esfera de los derechos humanos", y frente a los Estados miembros de las Naciones Unidas, cuando puede "formular recomendaciones respecto de la promoción y protección de los derechos humanos"14.

Remitiéndonos al artículo 38 del Estatuto de la Corte Internacional de Justicia ${ }^{15}$, éste enumera sólo aquellas normas de derecho que la Corte Internacional de Justicia debe aplicar cuando una controversia le es sometida, sin que se señalen como fuentes formales del Derecho Internacional

Los actos unilaterales de las Organizaciones Internacionales como lo son las resoluciones, recomendaciones, reglamentos o decisiones proferidas por éstas, omisión que se explica por la fecha de elaboración del estatuto (1920) , época en la que, aunque se conocía de manera primaria el fenómeno organizacional, nadie podía realmente prever en 1919 que un día las organizaciones internacionales podrían detentar un genuino poder legislativo (Gutiérrez, 1995, cap. 13).

Sin embargo, la extraordinaria proliferación en tiempos recientes de las organizaciones internacionales y sus órganos subsidiarios (para facilitar cierta descentralización administrativa), la diversidad de sus actos, creadores de obligaciones y compromisos internacionales en nuevos y amplios dominios, frente al carácter no exhaustivo del precitado artículo que no impide la aparición de nuevas fuentes del derecho producidas por el desarrollo de la sociedad internacional y de su progresiva organización, ha justificado que cierta parte de la doctrina y la jurisprudencia propongan, hoy en día, la inclusión de los actos unilaterales de los Estados y las organizaciones internacionales como fuentes formales, invitando en consecuencia a pensar en una posible reforma al artículo 38 del Estatuto de la Corte Internacional de Justicia.

Es claro que, desde su origen, las organizaciones internacionales poseen cierto poder normativo, que se puede ejercer en dos sentidos diferentes: en relación a los asuntos internos propios de la organización, pero también -y resulta ser el fenómeno más interesante y revolucionario- cuando estos actos son en relación a situaciones externas, potencialmente, capaces de crear obligaciones jurídicas para los estados miem-

13 Párrafo 5 de la Resolución 60/251.

14 Párrafo 5 numeral c) e i) de la Resolución 60/251.

15 Art. Artículo 38 del Estatuto de la Corte Internacional de Justicia, Carta de las Naciones Unidas.

1. La Corte, cuya función es decidir conforme al derecho internacional las controversias que le sean sometidas, deberá aplicar: a. las convenciones internacionales, sean generales o particulares, que establecen reglas expresamente reconocidas por los Estados litigantes; b. la costumbre internacional como prueba de una práctica generalmente aceptada como derecho; c. los principios generales de derecho reconocidos por las naciones civilizadas;

d. las decisiones judiciales y las doctrinas de los publicistas de mayor competencia de las distintas naciones, como medio auxiliar para la determinación de las reglas de derecho, sin perjuicio de lo dispuesto en el Artículo 59.

2. La presente disposición no restringe la facultad de la Corte para decidir un litigio ex aequo et bono, si las partes así lo convinieren. 
bros y en ocasiones -aunque a manera de excepción- incluso a Estados no miembros. A este respecto, cabe anotar que, el valor jurídico que se le reconoce a las resoluciones de las organizaciones internacionales es uno de los temas más polémicos y discutidos por la doctrina actual en derecho internacional.

Al Consejo de Derechos Humanos, como órgano subsidiario de la Asamblea General de las Naciones Unidas, entre sus funciones, según los términos de la Resolución 60/251 de la ONU, tiene la formulación de recomendaciones para el desarrollo del derecho internacional en cuanto a Ios derechos humanos en una doble dirección: a la Asamblea General y a los Estados miembros de la ONU. Pero si de lo que se trata es de mejorar el trabajo que venía desarrollando la Comisión de Derechos Humanos, icómo pretender tal objetivo cuando desde la perspectiva jurídica las resoluciones y recomendaciones que emite este órgano, no vinculan o no producen ningún efecto obligatorio frente a los Estados miembros y además, la carta constitutiva del nuevo Consejo de Derechos Humanos no les da un valor jurídico y un efecto preciso y diferente?

A pesar de la terminología existente aparentemente clara, en la práctica suscita algunas dificultades (Dupuy, 1993), pues vemos como existe cierto número de resoluciones que pueden producir efectos de derecho e incluso tener un carácter obligatorio, mientras que, algunas decisiones a pesar de su denominación podrán no producir efectos de derecho obligatorios y consistir en simples exhortaciones. Esta es una imprecisión terminología que ha reconocido la propia Corte Internacional de Justicia, por ello, el valor jurídico inmediato de las resoluciones proferidas al seno de una organización internacional será determinado en su carta constitutiva, un acuerdo posterior o una determinada práctica que haya dado lugar al nacimiento de normas consuetudinarias en la materia (Carreau, 2001).
Por lo anterior, tal dificultad práctica supone revisar cada caso en particular para poder determinar entre otros aspectos, la naturaleza jurídica de estos actos, la pretensión de la medida, el sentido del debate, los principios y fines del órgano internacional, por lo que corresponderá hacer un análisis del acta constitutiva y el acto en concreto para poder establecer su naturaleza y en consecuencia, sus efectos jurídicos.

Así se tiene que, revisando el contenido de la Resolución creadora del Consejo de Derechos Humanos, no existe ninguna indicación expresa en cuanto al alcance de los efectos jurídicos de los actos que van a ser emitidos por éste en él ejerció de su función.

Según la Carta de Naciones Unidas, la Asamblea General carece de competencia legislativa y sus declaraciones vienen a estar desprovistas de efectos jurídicos obligatorios para sus destinatarios. Sin embargo, al tenor de lo dispuesto en el artículo 17.2 las decisiones que determinan la distribución de los gastos del mismo órgano entre los miembros y las decisiones dictadas por el Consejo de Seguridad de acuerdo con el compromiso adquirido al tenor del articulo 25, pueden crear algunos derechos y obligaciones individuales para ciertos Estados, debiendo ser considerados estos actos verdaderos modos de creación de derecho. Por ello, se concluye que, cualquier otro acto objetivo expedido fuera de estas situaciones no podría ser considerado como fuente del derecho en ningún sentido del término (Carreau, 2001).

Es claro que el Consejo de Derechos Humanos a partir de sus competencias promoverá, formulará o prevendrá posibles violaciones a los derechos humanos, pudiendo posiblemente insistir en un método de interpretación, pero al tenor de lo expresado en el catálogo de funciones, no podrá imponer nunca la aplicación y observancia de sus recomendaciones o decisiones, pues al no 
señalarlo expresamente se entiende que esta clase de resoluciones no tiene carácter vinculante para sus miembros.

De otro lado, se observa también que el nuevo Consejo de Derechos Humanos, según la resolución 60/251, como órgano subsidiario de la Asamblea General, mantiene una relación directa con ésta, excluyendo toda comunicación o contacto con el Consejo de Seguridad, lo que hace que se pierda toda posibilidad de obligatoriedad de las decisiones y resoluciones que pueda proferir este órgano, y, en ese mismo sentido, concluimos que no puedan ser considerados estos actos como verdaderas fuentes de derecho internacional.

Así las cosas, las resoluciones recomendatorias de una organización internacional o un órgano subsidiario, carecen de todo valor jurídico como fuente autónoma del derecho internacional. Dichos actos constituyen una modalidad de soft law (término aparecido inicialmente en la literatura jurídica norteamericana hace una veintena de años), siendo necesario tener en cuenta que aunque si bien pueden, en principio, carecer de fuerza obligatoria, en un futuro servirán para preparar la aparición de verdaderas normas obligatorias (Sorensen, 2004).

En conclusión se tiene, entonces, que tal y como se afirma, el ordenamiento jurídico internacional es un ordenamiento imperfecto, contrario a lo que se predica respecto al derecho interno, por cuanto en derecho internacional la producción de normas generadoras de obligaciones y compromisos no tiene un centro de poder único, éste es, a todas luces, un sistema descentralizado en donde muchas veces sus autores resultan ser los mismos destinatarios tal y como ocurre en el seno de las organizaciones internacionales.
En consecuencia, la comunidad internacional en pleno espera que, obligatorios o no los actos que del Consejo emanan, los fines y propósitos que tiene fijados éste puedan materializarse y no lleguen a figurar como un conjunto de objetivos lejanos y difíciles de cumplir, insistiendo que, la consecución de sus fines y el cumplimiento de las obligaciones es un acto puramente voluntario de los Estados que reposa ante todo y solamente en la buena voluntad y la fuerza moral de los sujetos.

\section{EL CONSEJO DE DERECHOS HUMANOS EN RELACIÓN CON COLOMBIA}

\section{Antecedentes}

La Comisión de Derechos Humanos, gracias a la solicitud de varias organizaciones no gubernamentales nacionales e internacionales y a la presión de algunos Estados, durante su vigencia, le hizo un seguimiento permanente a la situación de los derechos humanos en Colombia ${ }^{16}$. Sin lugar a dudas, esta importante tarea debe continuarla y fortalecerla el Consejo de Derecho Humanos.

En 1996. debido a la gravedad de la situación en el país, la CDH, solicitó a la Oficina del Alto Comisionado de las Naciones Unidas para los Derechos Humanos que estableciera una oficina en Colombia, lo anterior, teniendo en cuenta la presión internacional y aprovechando la invitación del Gobierno del país ${ }^{17}$.

Dicha oficina fue establecida el 26 de noviembre de 1996, mediante acuerdo firmado por el Gobierno de ese país y el Alto Comisionado de las Naciones Unidas para los Derechos Humanos. En

16 La degradación del conflicto y la crisis política en Colombia son objeto de análisis interno y externo.
17 E/CN.4/2006/9 
el marco de este acuerdo, la oficina en Colombia debe observar la situación de los derechos humanos y del derecho internacional humanitario con el objeto de asesorar a las autoridades en la formulación y aplicación de políticas, programas y medidas para la promoción y protección de los derechos humanos, en el contexto de violencia y conflicto armado interno que vive el país y para hacerle, de esta manera, un seguimiento puntual desde las instancias de la ONU.

- Contexto nacional y evolución del conflicto armado interno en Colombia:

Según el informe de la oficina del Alto Comisionado para los Derechos Humanos en Colombia, la evolución del conflicto, se caracterizó por el mantenimiento de la ofensiva de las Fuerzas Militares contra la retaguardia de la guerrilla de las Fuerzas Armadas Revolucionarias de Colombia-Ejército del Pueblo (Farc-EP), así como por la persistencia de los grupos armados ilegales de atacar a los civiles ${ }^{18}$, situación que no ha variado hasta la fecha. Continuaron las desmovilizaciones de grupos paramilitares, con algunas interrupciones. No se observaron avances sustantivos para lograr la libertad de las personas en poder de las Farc-EP, a pesar de diversos esfuerzos nacionales e internacionales.

El informe citado deja constancia de que se ha reactivado el proceso de diálogos con la guerrilla del Ejército de Liberación Nacional (ELN), previéndose varios encuentros en el exterior entre el Gobierno y comandantes del ELN. El narcotráfico, el secuestro, la extorsión y el contrabando de gasolina continúan siendo la principal fuente de financiamiento de los grupos armados ilegales ${ }^{19}$.

- $\quad$ En cuanto a la situación de los derechos humanos $y$ del derecho internacional humanitario en Colombia, la situación se caracteriza por una serie de violaciones graves, vinculadas a los derechos civiles y políticos y a los retos pendientes en cuanto a los derechos económicos, sociales y culturales ${ }^{20}$.

Igualmente mencionan el informe, la existencia de un patrón de ejecuciones extrajudiciales y de desapariciones forzadas, asociadas a violaciones vinculadas a la administración de justicia y a la impunidad. Se registran detenciones arbitrarias, torturas y tratos crueles, inhumanos o degradantes, y atentados contra la libertad de expresión. Según la ONU, esas violaciones no forman parte de una política deliberada del Estado desde las más altas esferas, pero su escaso reconocimiento por las autoridades y la insuficiencia de acciones correctivas impiden superarlas. De otra parte, continúan existiendo violaciones de derechos humanos por a acción $u$ omisión de servidores públicos y a los familiares de las víctimas de las masacres en conductas perpetradas por paramilitares ${ }^{21}$.

Concluye el informe que, la situación de pobreza, que afecta a más de la mitad de los colombianos, y en particular los grupos étnicos, las mujeres y la niñez, muestra los altos grados de inequidad, reflejados en el acceso y goce de los derechos a la educación, a la salud, al empleo y a la vivienda, entre otros. En Colombia, puede observarse la persistencia de graves infracciones

\footnotetext{
18 linforme de la Alta Comisionada de las Naciones Unidas para los Derechos Humanos sobre Colombia, (año 2005) presentado a la Comisión de Derechos Humanos durante su $61^{\circ}$ período de sesiones en el 2006. 
cometidas por los grupos armados ilegales, en particular las Farc-EP y los paramilitares de las Autodefensas Unidas de Colombia (AUC) ${ }^{22}$.

Téngase en cuenta, que uno de los principios del Sistema de las Naciones Unidas, es el de la cooperación entre los Estados y entre los órganos que la componen; en ese sentido al Consejo de Derechos Humanos le corresponde dentro de su mandato continuar con el seguimiento al conflicto interno en Colombia, la oficina del Alto Comisionado de los Derechos Humanos en Colombia presenta una serie de recomendaciones hechas al gobierno nacional las cuales se han implementado en mayor o menor grado, reco- mendaciones a las cuales el CDH le hará un estricto seguimiento ${ }^{23}$.

Es de esperar que con las nuevas herramientas institucionales que posee el $\mathrm{CDH}$, (en términos de eficiencia y eficacia), deberá tomar las medidas necesarias para que en nuestro país se respeten las normas internacionales y nacionales en materia de derechos humanos y del derecho internacional humanitario. Es de vital importancia para el logro de estos fines, que el país supere cuanto antes, el conflicto armado interno por medio de diálogos y negociaciones que desde el comienzo prioricen el respeto del derecho internacional humanitario y los derechos humanos.

22 Con sus acciones incumplen las normas humanitarias al atacar a la población civil. Las guerrillas, en particular de las Farc-EP y en menor medida el ELN, continúan cometiendo homicidios, masacres, actos de terrorismo, amenazas y ataques a la población civil, toma de rehenes, utilización de minas antipersonal, reclutamiento de niños y niñas y ataques a misiones médicas. De otra parte, los paramilitares violaron repetidamente su compromiso de cese de hostilidades y persistieron en la comisión de homicidios, amenazas y ataques contra la población civil, toma de rehenes, tortura y tratos humillantes y degradantes, desplazamientos forzados, reclutamiento de niños y niñas y actos de violencia sexual. A los miembros de la Fuerza Pública, y en particular del Ejército, se les atribuyen infracciones al principio de distinción, entre ellas, por la utilización de niños como informantes y en otras actividades militares, así como el uso de escuelas y viviendas civiles, así como actos de violencia sexual.

Varios grupos particularmente vulnerables fueron afectados por la acción violenta de los grupos al margen de la ley en el contexto del conflicto armado interno, así como por violaciones a sus derechos y libertades fundamentales. Algunas políticas y el comportamiento de ciertos servidores públicos también afectaron la situación de esos grupos. Entre ellos puede citarse a los defensores de derechos humanos, miembros de organizaciones de mujeres y de víctimas, líderes comunitarios y de desplazados, y sindicalistas. Igualmente, comunidades en riesgo, como las desplazadas y las bloqueadas, así como las comunidades indígenas y afrocolombianas y otras minorías étnicas se vieron especialmente afectadas y fueron víctimas de violaciones e infracciones. A estos se agregan por su especial vulnerabilidad, la niñez, las mujeres, las personas pertenecientes a minorías sexuales, periodistas, miembros y líderes de partidos políticos, objetores de conciencia, personas detenidas, rehenes y desaparecidos, así como autoridades locales y operadores de justicia.

El paramilitarismo sigue teniendo fuerte influencia en varias regiones del país, controlando aspectos políticos, económicos y sociales. Se registraron incumplimientos del cese de hostilidades, el reclutamiento de nuevos miembros y la conformación de nuevos grupos.

23 La oficina en Colombia continúa impulsando la implementación de las recomendaciones del Alto Comisionado.

- En materia de prevención y protección, se tomaron algunas medidas positivas, como la adopción de protocolos para regular ciertos procesos de Comité Interinstitucional de Alertas Tempranas (CIAT) y el incremento del presupuesto para los programas de protección del Ministerio del Interior. Sin embargo, continúan existiendo debilidades en el campo operativo para hacer el seguimiento a las alertas, así como a tardanzas e ineficacia en la evaluación de los riesóos.

- La emisión de una circular sobre el respeto del trabajo individual y colectivo de los defensores de derechos humanos no ha cubierto adecuadamente la recomendación de sancionar los incumplimientos de las directivas presidenciales en la materia.

No se observaron avances concretos para la revisión de los archivos de inteligencia.

Se adoptaron algunas medidas destinadas a 2 de las 12 comunidades indígenas en riesgo de extinción incluidas en las recomendaciones. Se observaron esfuerzos importantes para atender los requerimientos de la Corte Constitucional para la debida atención de los desplazados, aunque continúa siendo necesario seguir avanzando

- Los grupos armados al margen de la ley continuaron incumpliendo abiertamente las recomendaciones del Alto Comisionado. Las Fuerzas Militares, en sus operaciones, en ocasiones, han desconocido los principios humanitarios de distinción, limitación y proporcionalidad.

- Se destaca la adopción de algunas normas, la ratificación de tratados internacionales y progresos en la elaboración del Plan de Educación en Derechos Humanos.

- En cuanto al Plan Nacional de Acción en Derechos Humanos no se logró avanzar en la medida de lo esperado. Lo mismo se observó respecto de las recomendaciones dirigidas al Ministerio del Interior y de Justicia y el Instituto Nacional Penitenciario (INPEC). En materia de impunidad, la Fiscalía y la Procuraduría General adoptaron algunas acciones.

- Continúa siendo preocupante el bajo número de sentencias, la poca efectividad de las investigaciones sobre responsabilidad de servidores públicos y la asunción indebida de casos por la justicia penal militar.

En noviembre la Oficina suscribió un acuerdo de cooperación con el Ministerio de Defensa para el estudio sobre los avances en la enseñanza de los derechos humanos y el derecho internacional humanitario de manera integral, sistemática y operacional. Poco se avanzó en cuanto a sancionar los vínculos de servidores públicos con paramilitares y a desmantelar efectivamente el paramilitarismo. 


\section{TRASCENDENCIA ESTRATÉGICA DEL CONSEJO DE DERECHOS HUMANOS}

El Consejo $(\mathrm{CDH})$ según los análisis internos de la ONU, las observaciones de los Estados miembros y las ONG, tiene un gran potencial para ser más sólido y eficaz que el órgano que lo precedió. Para cumplir con sus objetivos, los países miembros del Consejo, los gobiernos observadores y otros participantes dentro del mismo, deben prestar su concurso para que ese potencial se convierta en una realidad.

Las conclusiones de los exámenes a los que se están sometiendo los países miembros del Consejo de Derechos Humanos ayudaran a la Comunidad Internacional a mejorar la asistencia técnica y el asesoramiento sobre políticas que proporciona dicho Consejo. Además, contribuirían a que Ios miembros elegidos para hacer parte del $\mathrm{CDH}$, se responsabilicen por el cumplimiento de sus compromisos en materia de derechos humanos.

Uno de los principios del Sistema de las Naciones Unidas, es el de la cooperación entre los Estados y entre los órganos que lo componen. En ese sentido, al Consejo de Derechos Humanos le corresponde, dentro de su mandato, continuar con el seguimiento al conflicto interno en Colombia. Con las nuevas herramientas institucionales que posee, en términos de eficiencia y eficacia, el $\mathrm{CDH}$, deberá tomar las medidas necesarias para que en nuestro país se respeten las normas internacionales y nacionales en materia de derechos humanos y de derecho internacional humanitario. Pero, es de vital importancia para el logro de estos fines, que el país supere el conflicto armado interno, por medio de diálogos y negociaciones, que desde el comienzo prioricen el respeto del derecho internacional humanitario y los derechos humanos.

El CDH deberá desempeñar un papel central en la supervisión y la contribución a la interpretación y la elaboración de normas internacionales sobre derechos humanos. El derecho internacional y las normas internacionales son una parte fundamental del sistema de las Naciones Unidas para la protección de los derechos humanos; en efecto, el cuerpo de normas internacionales en esta materia, elaboradas por la Comisión fueron su principal legado; el Consejo de Derechos Humanos, en su carácter de órgano permanente, podrá encontrar formas de superar las demoras que enfrento la Comisión en relación con algunas actividades normativas.

Sin lugar a dudas, el CDH reforzará la labor fundamental del sistema de órganos creados en virtud de tratados, que han contribuido significativamente al desarrollo del derecho internacional durante los últimos veinte años y podrá ayudar en el proceso de racionalización y fortalecimiento del sistema de la ONU para cumplir mejor su mandato. Sin embargo, revisando el contenido de la resolución creadora del Consejo de Derechos Humanos no existe ninguna indicación precisa en cuanto al alcance de los efectos jurídicos de los actos emitidos por éste, a pesar de la terminología existente aparentemente clara, que en la práctica suscita algunas dificultades.

Es necesario anotar que los Estados y sus respectivos gobiernos deben demostrar no sólo con sus palabras, sino también con sus actos, que están preparados para hacer del Consejo un órgano más firme y eficaz para la promoción y la protección de los derechos humanos de lo que fue la Comisión.

Como órgano político compuesto por gobiernos, el Consejo dependerá mucho de que sus miembros creen una institución que los anime a propiciar más decididamente el respeto hacia los derechos humanos por encima de los intereses políticos, que tanto daño le hicieron a la credibilidad de la antigua Comisión. En ese sentido, de- 
ben comenzar seriamente a establecer procedimientos y métodos de trabajo que permitan al Consejo conseguir la meta de garantizarle a todos, el disfrute real de todos los derechos humanos.

Otro aspecto relevante del $\mathrm{CDH}$, es el hecho de tener un mandato claro:

- Promover y proteger los derechos humanos, lo que supone ocuparse de las violaciones graves y sistemáticas, contribuir a evitar dichas violaciones y responder sin demora a emergencias en esta materia. Además, no cabe duda de que su mandato se aplica a todas las situaciones y en todos los países. Es así, como la Carta Constitutiva del Consejo de Derechos Humanos le asigna como principal función la "promoción del respeto universal de la protección de todos los derechos humanos y libertades fundamentales de todas las personas, sin distinciones de ningún tipo y de forma justa y equitativa".

Una de las nuevas herramientas del Consejo es un mecanismo de examen periódico universal, es decir, que todos los Estados miembros de la ONU deben pasar por esta evaluación del cumplimiento de sus obligaciones en materia de derechos humanos. El Consejo debe proceder con energía y valor para establecer las modalidades del examen periódico universal que garantizara que no sea posible evadir su responsabilidad ante lamentables situaciones de derechos humanos, por el hecho de que sucedan en países poderosos o en países con amigos poderosos.

- La Asamblea General de la ONU, al crear el Consejo, hizo mucho hincapié en la importancia del diálogo internacional constructivo y la cooperación con éste en su trabajo. Al estar de acuerdo en que el Consejo debe poner el énfasis en ayudar a los países que están dispuestos a dejarse ayudar para po- der cumplir con sus obligaciones en materia de derechos humanos. Pero cuando los países se nieguen a cooperar con él, debe poder recurrir a otros medios para reafirmar, que el respeto por los derechos humanos es una obligación internacional.

Finalmente debemos mencionar que entre las fortalezas que tenía la Comisión y que el Consejo ha heredado, están los Procedimientos Especiales y las prácticas y disposiciones que permiten la participación activa de las ONG y las instituciones nacionales de derechos humanos sin lo cual la misión del CDH se tornaría mucho más difícil de lo que ya es suyo.

\section{BIBLIOGRAFÍA}

Alexei, J. (2000). Los Derechos fundamentales entre particulares. Universidad Externado de Colombia.

Amnistía Internacional informes. Autor.

Asamblea General de la ONU. Resolución 60/251, aprobada el 15 de marzo de 2006 por un Consejo de Derechos Humanos. Autor.

Ballesteros, J. (1992). Derechos humanos. Madrid: Editorial Technos.

Carta de las Naciones Unidas

Cepeda, M. (1997). Los derechos fundamentales en la Constitución de 1.991. Bogotá: Editorial Temis.

Carreau, D. (2001). Les actes unilatéraux des organisations internationales. En Droit International. Chapitre II. Paris.

Comisión Colombiana de Juristas 
Constitución Política de Colombia

Defensoría del Pueblo informes defensoriales, 2004-2005.

Dupuy, P. M. (1993). Droit international publique. Les sortilèges de la soft law. Paris.

Estatuto de la Corte Internacional de Justicia

Ferrajoli, L. (1995). Derecho y razón. Madrid: Editorial Trotta.

Fleiner, T. (1999). Derechos humanos. Bogotá: Editorial Temis.

Galvis, L. (1996). Comprensión de los derechos humanos. Bogotá: Ediciones Aurora.

Gutierrez, E. (1995). Otras fuentes de normas y obligaciones no mencionadas en el articulo 38 de la Corte Internacional de Justicia. Cesáreo Derecho internacional público. Capitulo 13. Madrid: Editorial Trotta.

Organización de las Naciones Unidas informes
Ortiz, H. (2001). Cartilla de los derechos humanos. Bogotá: Ediciones Gustavo Ibáñez.

Los derechos humanos, reflexiones y normas. (1994). Editorial Temis.

Papacchini, Á. (1997). Los derechos humanos, un desafío a la violencia. Bogotá: Altamir ediciones.

Quiroga, H. (1995). Los derechos humanos y su defensa ante la justicia. Bogotá: Editorial Temis.

Roulet, F. (1997). Manual sobre el sistema de las Naciones Unidas. Copenhague: Editorial Florencia Roulet e Iwgia.

Saavedra, E. et al. (1995). Derecho penal internacional. Tomo I y II. Ediciones jurídicas Gustavo Ibáñez.

Sorensen, M. (2004). Manual de derecho internacional publico. (Reimpresión) Fuentes del Derecho Internacional. México: Fondo de Cultura Económica. 